\title{
On finding striated muscle in the brain
}

\author{
STEPHEN F. HOFFMAN ${ }^{1}$ AND LUCY BALIAN RORKE
}

From the Department of Neurology, The Pennsylvania Hospital, and the Department of Pathologic Anatomy, The Children's Hospital of Philadelphia, Philadelphia, Pennsylvania, U.S.A.

SUMMARY Well-developed striated muscle was found in the leptomeninges of a 2 day old infant with a 13-15 trisomy defect and multiple congenital anomalies. Except for arhinencephaly, minor sulcal abnormalities, and scattered microscopic cerebellar dysplasias the brain was well formed. The extreme rarity of this finding is noted and an attempt is made to explain it on an embryological basis. The implications of this observation in relation to some central nervous system tumours containing striated muscle are briefly discussed.

Identification of normal tissue in areas of the body where it is not usually found generally excites the curiosity of the observer, and demands a rational scientific explanation. Occasionally one may be found, but in most instances we must satisfy ourselves with the most acceptable of several theoretical possibilities.

Routine examination of the brain of a 2 day old infant with a chromosomal abnormality of the 13-15 trisomy type and multiple congenital anomalies disclosed the presence of striated muscle fibres in the leptomeninges overlying the ventral surface of the pons.

\section{CASE REPORT}

J.C. was born to a 42 year old mother whose only other pregnancy 14 years previously had produced a normal child. The pregnancy was complicated by a threatened abortion in the first trimester, and delivery was accomplished by Caesarean section at approximately 34 weeks' gestation.

The infant weighed $1.8 \mathrm{~kg}(4 \mathrm{lb}$.) and was both cyanotic and hypotonic at birth. Multiple congenital anomalies were noted, including an omphalocoele, cleft lip and palate, midline occipital scalp defect, rudimentary sixth digit on both hands, a sixth toe on the right foot, a coloboma of the iris with partial lens opacity O.D., and a 13-15 trisomy defect (confirmed by karyotyping).

The omphalocoele was repaired successfully, but the postoperative course was complicated by hypoglycaemia, apnoeic spells and seizures, and the baby died at the age of 2 days.

General post mortem examination disclosed the above

'Supported in part by training grant in Neurology N.I.N.D.S., N.I.H., 2TINB5410-08. noted defects. In addition, there were numerous abnormalities of the cardiovascular, genitourinary, dermal, haematological, and musculo-skeletal systems, all felt to be consistent with the diagnosis of trisomy 13-15.

Gross examination of the brain showed two separate cerebral hemispheres and a normal convolutional pattern over the vertex and convexities. There were minor sulcal abnormalities involving the cingulate gyrus, the medial parietal lobe, and the temporal lobes. The olfactory bulbs and tracts were absent and both optic nerves were small and grey. The inferior vermis was absent.

The major microscopic abnormalities consisted of dysplastic cerebellar cell rests of various types, fibrillary gliosis, primarily of cerebral white matter, and extramedullary neural tissue in the basal leptomeninges. At the level of the optic chiasm, this consisted of a glialvascular stroma throughout which were scattered welldeveloped neurones. Leptomeninges ventral to the pons also contained glial-vascular tissue in which multiple striated muscle fibres were seen (Figs. 1 and 2). Some of these could be traced into the pontine parenchyma along with the penetrating vessels (Fig. 3).

\section{DISCUSSION}

The identification of non-neoplastic striated muscle fibres in the cerebral leptomeninges must be regarded as a phenomenon which occurs with extreme rarity. Marsden (1971) observed striated muscle in the leptomeninges adjacent to the medulla in an individual with Klippel-Feil syndrome with hydrocephalus. All other reported instances of heterotopic mesenchymal tissues in the nervous system have been in the form of 'tumours'. Eberth (1898) found a small mass on the inner surface of the dura mater from a 70 year old woman. This consisted of lymphoid tissue, fat cells, striated muscle fibres, and 


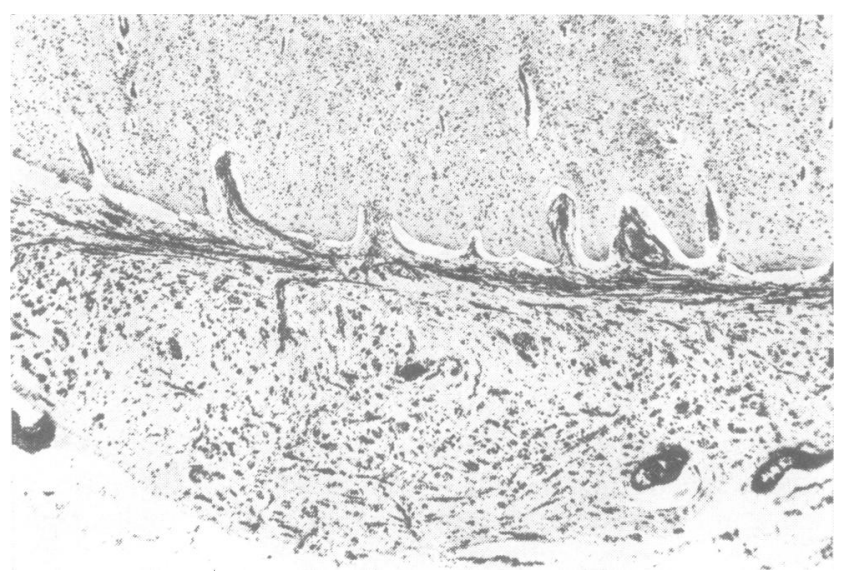

FIG. 1. Thickened leptomeninges ventral to basis pontis containing striated muscle fibres cut both in longitudinal and crosssection. Note penetration of muscle fibres into pontine parenchyma along with the perivascular tissues. Phosphotungstic acid haematoxylin $(P T A H)$ stain, $\times 60$.

nerve bundles. Three additional examples of such tumours have been found in relation to the spinal meninges. Gowers (1876) reported a conus medullaris-cauda equina mass composed of adipose tissue and scattered striated muscle fibres, which he thought had arisen from the pia mater. Two additional examples of 'teratoid tumours' of the spinal theca noted by Hosoi (1931) also contained striated muscle.

There has been a difference of opinion regarding the precise categorization of these abnormal tissue growths as teratomas or heterotopias. Willis (1962) is of the opinion that they belong in the latter group.

In addition to these rare benign central nervous ${ }_{\perp}$ system masses containing striated muscle, some malignant tumours have also been described in which $/ 2$ a variable number of muscle fibres were identifieg. These include the so-called medullomyoblastonga (Marinesco and Goldstein, 1933) and the primas $\overrightarrow{2}$ cerebellar rhabdomyosarcomas (Lopes de Fari⿺辶, 1957).

When found in such tumours, the origin of the

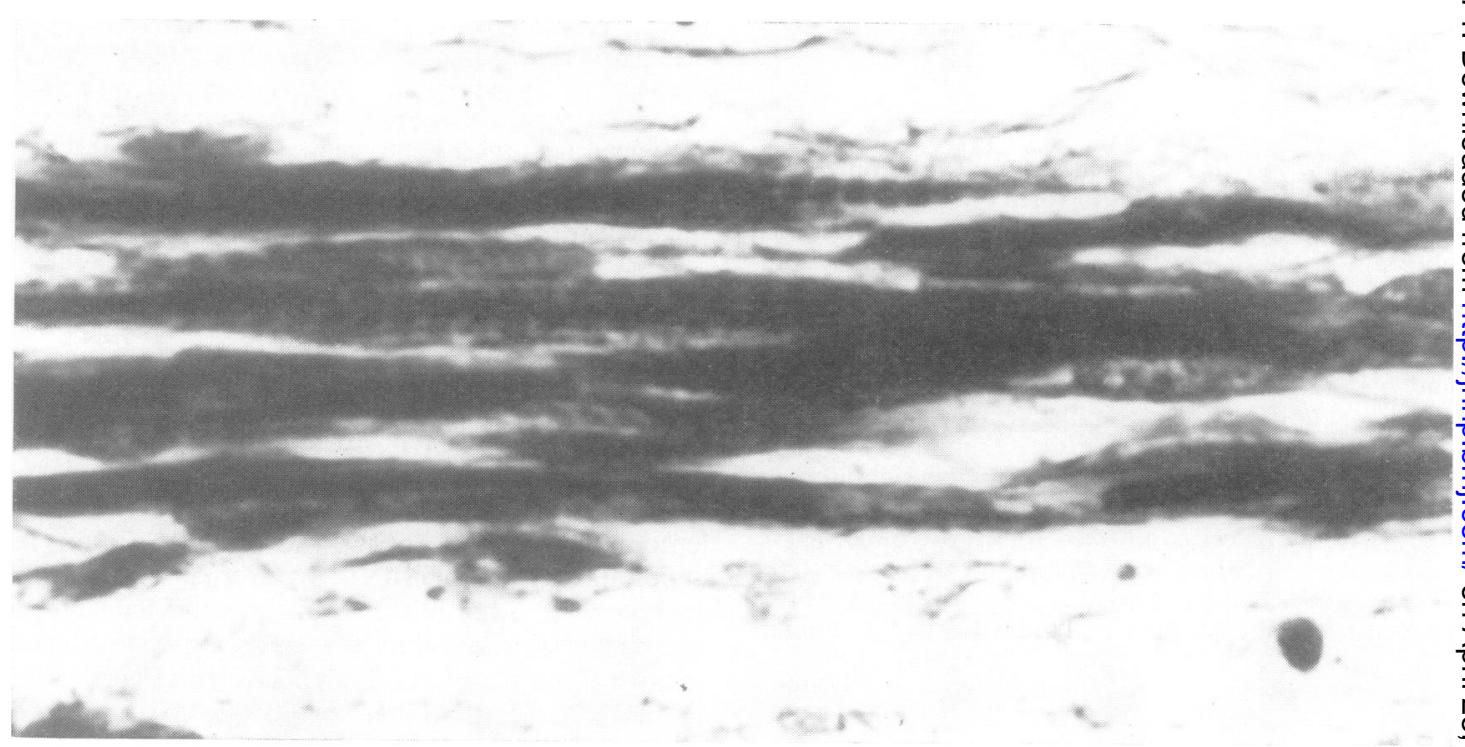

FIG. 2. High magnification of well-developed striated muscle fibres in basal leptomeninges. PTAH stain, $\times 1,000$. 


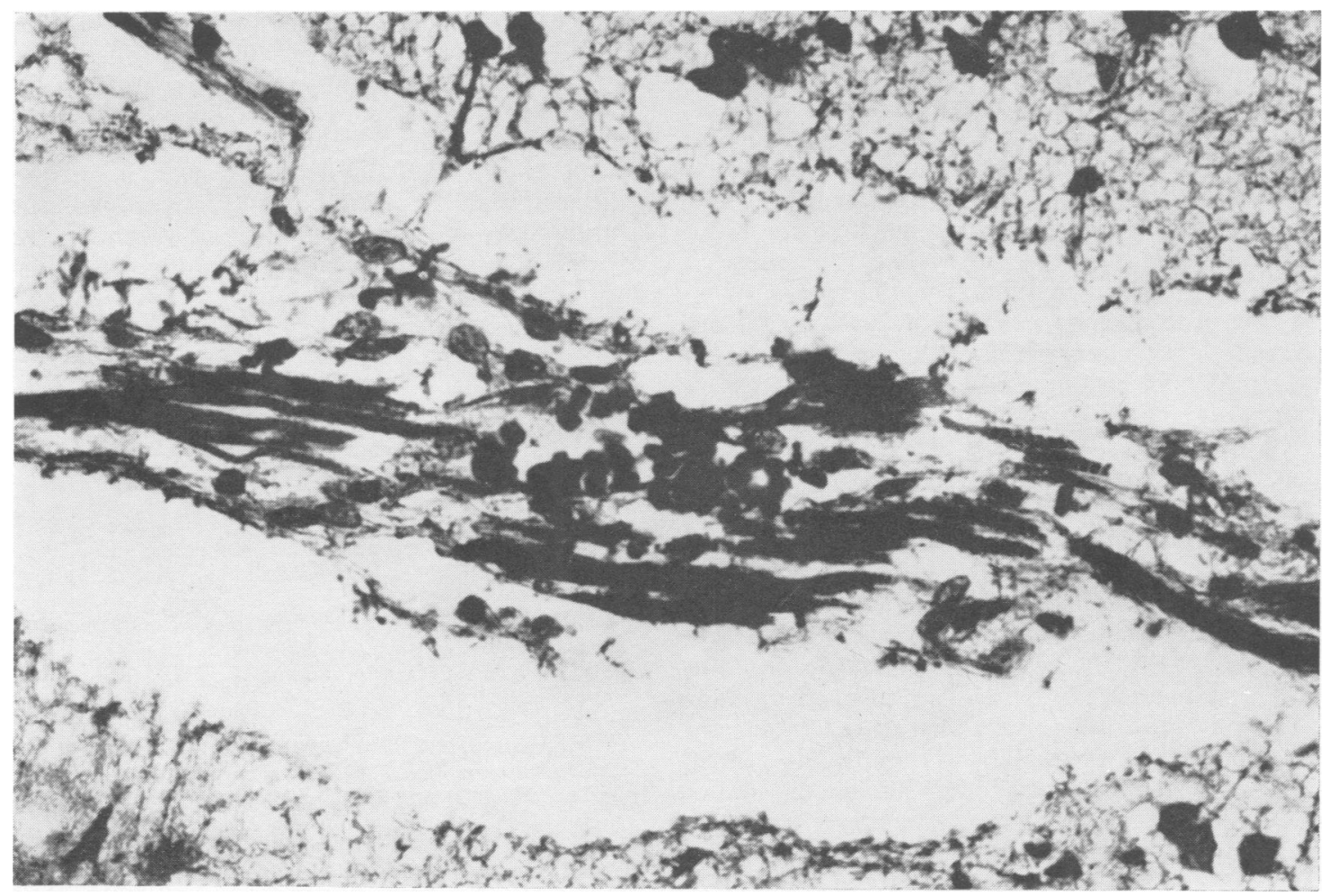

FIG. 3. Striated muscle fibres in perivascular tissue of blood vessel in basis pontis. PTAH stain, $\times 500$.

striated muscle has been uncertain, although several possibilities have been suggested. Lopes de Faria (1957) favoured an origin from undifferentiated perivascular mesenchymal cells, whereas Marinesco and Goldstein (1933) suggested either a process of 'dysembryogenesis' or metaplasia from smooth muscle fibres. Alternatively, relegation of tumours containing striated muscle into the teratoma group was suggested by Ingraham and Bailey (1946).

Willis's (1962) careful analysis of muscular metaplasia led him to reject the possibility that striated muscle can be formed by metaplasia of smooth muscle, and he further stated that he knew of no non-neoplastic instance of metaplastic formation of striated muscle from non-muscular cells. In his opinion it is probable that 'aberrant differentiation has taken place in tumor cells arising from some other mesenchymal tissue'.

While the origin of striated muscle fibres in tumours remains unsettled, we now have the added task of explaining their non-neoplastic appearance in the central nervous system.

Review of the embryology of the leptomeninges and the striated muscle of the head provides a rational explanation for what superficially appears to be an anatomical curiosity (Hörstadius, 1950; Hamilton, Boyd, and Mossman, 1962; Bloom and Fawcett, 1968).

Studies reviewed and reported by Hörstadius (1950) in his monograph on the neural crest indicate that the multipotential cells comprising this embryonic structure give rise to a diversity of tissues in the mature organism. These include the cranial and spinal sensory ganglia, the leptomeninges, the sheath cells of Schwann, melanoblasts, argentaffin cells of the intestinal tract, branchial cartilage, and the head mesenchyme.

Although striated muscle in the rest of the body is derived embryologically from the paired somatic myotomes, the muscles of the head region are formed from mesenchyme (Bloom and Fawcett, 1968), which is a derivative of the special ectomesenchyme of the neural crest. From the strictly developmental point of view, therefore, it is theoretically possible to find striated muscle in the leptomeninges, since both types of tissue are derived from the neural crest mesen- 
chyme. That this observation has not previously been recorded is no doubt a function of the extreme rarity of its occurrence.

These facts suggest the possibility that embryonic neural crest cells may serve as precursors for some central nervous system tumours which contain seemingly foreign tissue elements. Acceptance of the hypothesis that such tumours originate from multipotential primitive cells rather than from those of more advanced differentiation would resolve many baffling problems. As a matter of fact, Crue (1958) offered this explanation for the diverse morphological features encountered in medulloblastomas.

It is beyond the scope of this limited presentation to delve into detailed aspects of the cell of origin of the medulloblastoma. Many observers are of the opinion that they arise from the foetal external granular layer of the cerebellar cortex (Stevenson and Echlin, 1934; Kadin, Rubinstein, and Nelson, 1970) or from residual embryonic cell rests in the region of the posterior medullary velum (Raff and Kernohan, 1944). On the other hand, Gullotta (1967), in a reappraisal of the derivation of medulloblastomas, presents the thesis that these tumours are type specific mesenchymal tumours of the central nervous system. Among other things, he draws attention to the close morphological resemblance between the medulloblastoma and nephroblastoma (Wilms's tumour). Both are composed of embryonicappearing cells, each shows a variable degree of rosette formation and striated muscle fibres are occasionally found in both. Of interest in this connection is Masson's (1938) theory that the nephroblastoma is of neural crest origin!

There is presently little evidence in support of Masson's view; however, Crue's suggestion that the medulloblastomas may arise from residual neural crest cells remains attractive. Aside from the fact that it would explain the appearance of striated muscle in the so-called medullomyoblastomas, it is also consistent with the finding that some medulloblastomas bear a strong resemblance to tumours arising in the adrenal medulla or other peripheral neural structures-the embryological origins of which are generally accepted as of neural crest derivation. On the other hand, considering the fact that both the neural crest and the cerebellum arise from the dorsal part of the alar plate it is perhaps not surprising that tumours derived from them occasionally contain histological features in common.
While a single demonstration of the non-neoplastic occurrence of striated muscle in a portion of the brain derived from the neural crest does not prove or disprove anything, it does provide an additional small piece of evidence in favour of the view that the totipotential cells of the neural crest or those from the dorsal part of the alar plate from which both the neural crest and the cerebellar primordium are derived deserve more careful scrutiny from the morphologist than they have hitherto enjoyed.

\section{REFERENCES}

Bloom, W., and Fawcett, D. W. (1968). A Textbook of Histology, 9th edn. Saunders: Philadelphia.

Crue, B. L., Jr. (1958). Medulloblastoma. Thomas: Springfield, Ill.

Eberth, C. J. (1898). Intracranielles teratom mesodermalen Ursprungs. Virchows Arch. path. Anat., 153, 71-74.

Gowers, W. R. (1876). Myo-lipoma of spinal cord. Trans. path. Soc. (Lond.), 27, 19-22.

Gullotta, F. (1967). Das Sogenannte Medulloblastom (Monographien aus dem Gesamtgebiete der Neurologie? und Psychiatrie, Heft 118). Springer: Berlin.

Hamilton, W. J., Boyd, J. D., and Mossman, H. W. (1962) Human Embryology, 3rd edn. Heffer: Cambridge.

Hörstadius, S. O. (1950). The Neural Crest. Oxford University Press: London.

Hosoi, K. (1931). Intradural teratoid tumors of the spina cord. Report of a case. Arch. Path., 11, 875-883.

Ingraham, F. D., and Bailey, O. T. (1946). Cystic teratomas and teratoid tumors of the central nervous system in infancy and childhood. J. Neurosurg., 3, 511-532.

Kadin, M. E., Rubinstein, L. J., and Nelson, J. S. (1970): Neonatal cerebellar medulloblastoma originating from the fetal external granular layer. J. Neuropath. exp. Neurol. 29, 583-600.

Lopes de Faria, J. (1957). Rhabdomyosarcoma of cerebellum. Arch. Path., 63, 234-238.

Marinesco, G., and Goldstein, M. (1933). Sur une forme anatomique, non encore décrite, de Médulloblastome: médullo-myo-blastome. Ann. Anat. path., 10, 513-525.

Marsden, H. G. (1971). Unpublished observation.

Masson, P. (1938). The rôle of the neural crests in the embryonal adenosarcomas of the kidney. Amer.J. Cancer, 33, 1-32.

Raff, J., and Kernohan, J. W. (1944). Relation of abnormal collections of cells in posterior medullary velum of cerebellum to origin of medulloblastoma. Arch. Neurol. Psychiat. (Chic.), 52, 163-169.

Stevenson, L., and Echlin, F. (1934). Nature and origin of some tumors of the cerebellum. Medulloblastoma. Arch. Neurol. Psychiat. (Chic.), 31, 93-109.

Willis, R. A. (1962). The Borderland of Embryology and Pathology, 2nd edn. Butterworths: London. 